\title{
Discriminación a los consumidores: una valoración a partir de la Ley española de competencia desleal
}

\section{discrimination of consumers: an evaluation from the spanish unfair competition law}

\author{
Elisabet González Pons ${ }^{\mathrm{I}}$
}

\section{RESUMEN}

La regulación española de discriminación a los consumidores en la Ley de competencia desleal queda desubicada del Capítulo III de la Ley dedicado a las prácticas comerciales con consumidores, a pesar de que estos sean su objeto de protección. El trabajo analiza la citada regulación, los pronunciamientos judiciales sobre esta cuestión y reflexiona sobre nuevas formas de discriminación a los consumidores al amparo de la citada normativa.

Palabras clave: Discriminación - consumidores y usuarios - prácticas comerciales desleales - Directiva 2005/29/CE

\section{ABSTRACT}

The Spanish regulation of discrimination against consumers in the Unfair Competition Law has been misplaced from Chapter III of the Law about commercial practices with consumers even though consumers are the subjects that protect the article. The paper analyses the regulation, judicial pronouncements on this issue and reflects on new forms of discrimination against consumers under the aforementioned regulation.

Keywords: Discrimination - consumers and users - unfair commercial practices - Directive 2005/29/EC.

Elisabet González Pons. Doctora en Derecho e Investigadora Postdoctoral, Universidad de Valencia, Espańa.

Correo electrónico: elisabet.gonzalez@uv.es. 


\section{Introducción: antecedentes y actual regulación española contra la competencia desleal}

En el ordenamiento español los actos de competencia desleal se regulan en la Ley 3/1991, de 10 de enero, de Competencia Desleal (en adelante, LCD). Con anterioridad a la promulgación de esta norma, el marco normativo español para la represión de conductas desleales se había caracterizado por una gran dispersión normativa plagada de imperfecciones y marcadas deficiencias que habían puesto en entredicho su escasa utilidad para la persecución de conductas anticoncurrenciales. ${ }^{2}$

La aprobación en los inicios de la década de los noventa de la LCD (1991), supuso la adopción de un instrumento capaz de crear un marco jurídico cierto y efectivo con el que luchar contra las prácticas incorrectas contrarias al sistema de competencia. ${ }^{3}$ Así lo advertía el legislador español en el extenso Preámbulo de la Ley. El nuevo instrumento jurídico esperaba aportar el aire fresco que necesitaba la disciplina, tras la dictadura franquista, con una Ley que se proponía representar la culminación que la regulación de la competencia desleal había experimentado en España hacia un modelo, denominado social, de competencia desleal, en el que no se atendía únicamente al interés de los profesionales en el que no sucedieran prácticas anticompetitivas en el mercado, sino que se atendiera al interés de todos los que intervenían en el mercado a luchar contra la competencia desleal. ${ }^{4}$

En el momento de la redacción de la LCD (1991) España veía con optimismo su apertura hacia nuevos mercados que la posicionaran finalmente en el contexto internacional. Además, la mayor sensibilidad de los hombres de empresa —expresión con la que se conocía a los empresarios- hacia la innovación de las estrategias comerciales, había abierto nuevas perspectivas en la economía española, pero simultáneamente había hecho aflorar abusos en el mercado.

Asimismo, el ingreso de España en la Comunidad Económica Europea exigía la homogeneización de la legislación represora de la competencia desleal española con las legislaciones imperantes en los restantes Estados miembros. Por eso, la Ley también obedecía a la necesidad de adecuar el ordenamiento competencial a los valores en los que la Constitución española basaba el sistema económico, a saber, el principio de libertad de empresa y el principio de libertad de competencia, con el mandato expreso al legislador de impedir que el principio de libertad de competencia pudiese verse falseado por prácticas desleales susceptibles de perturbar el correcto funcionamiento del mercado.

Por todas estas consideraciones, la LCD de 1991 fue considerada como una gran oportunidad para configurar un cuerpo normativo que aglutinara sin discriminación la protección de todos los intereses que resultan afectados por la competencia desleal. Sin embargo, el nuevo rumbo que había tomado la disciplina se puso ya en duda desde los comienzos de la implantación de la Ley, ${ }^{5}$ en base a dos razones fundamentales:

1) Se cuestionó si el nuevo cuerpo legislativo aprobado realmente conseguiría responder a los conflictos que se generarían entre sujetos que no eran empresarios, es decir, si sería un instrumento para atajar las prácticas desleales de los empresarios con los consumidores, o simplemente serviría para la represión

\footnotetext{
Fernández-Nóvoa (1978) pp. 13 y ss., y Gómez Segade (1974) p.389 y ss.

Preámbulo de la LCD (1991). También, Massaguer Fuentes (1999) pp. 55 a 58.

Ménendez Menéndez (1988) pp. 31 y ss.

Otero Lastres (1991-1992), ADI, No 14, p. 30.
} 
de las conductas desleales de los empresarios competidores directos como tradicionalmente se había concebido la configuración de la disciplina de la competencia desleal.

2) Se dudó de su capacidad para poner término a la situación de incertidumbre que había imperado durante tanto tiempo en el marco normativo del Derecho represor de la competencia desleal en Espańa, tal y como la Ley anunciaba en su preámbulo.

Pese a estos cuestionamientos iniciales, nada impide afirmar que la LCD (1991) supuso un avance fundamental en la disciplina de la competencia desleal en España, pues entre sus logros se cuenta el fortalecer una disciplina fragmentada y obsoleta incapaz de dar respuesta a nuevas prácticas anticompetitivas que habían implicado un profundo deterioro del tráfico jurídico mercantil español. Se configuró asimismo como un instrumento con vocación de permanencia, porque mediante la aprobación de la cláusula general de deslealtad en los términos en los que fue redactada: «Se reputa desleal todo comportamiento que resulte objetivamente contrario a las exigencias de la buena fe» (ex art. 5 LCD), permitía acomodarse en cada momento a la cambiante realidad económica del contexto de mercado, y susceptible de ser aplicada a cualquier actividad, superando así las restricciones de las otras normas reguladoras de la materia con anterioridad. La Ley se completaba con un exhaustivo listado de acciones y remedios procesales para reprimir las prácticas anticoncurrenciales.

La estructura elegida para afrontar la regulación de la competencia desleal en España no era exclusiva del legislador español, sino que se trataba de un modelo que tomaba prestado, en particular, el modelo alemán. Así, la primera redacción de la LCD se configuraba de la siguiente manera:

En primer lugar, se establecían unas disposiciones generales, que fijaban su finalidad, su ámbito objetivo, subjetivo y territorial de aplicación (arts. 1, 2, 3 y 4 respectivamente). ${ }^{6}$ A continuación, la Ley contenía una cláusula general prohibitiva de la competencia desleal (art. 5) basada en los criterios de la buena fe y un listado de actos que, en particular, se consideraban actuaciones contrarias a la leal competencia (arts. 6 a 17), centrándose en un régimen unitario en el que no se distinguía entre los sujetos afectados por un acto de competencia desleal. Además, la Ley se esforzaba por configurar mecanismos sustantivos y procesales para un adecuado tratamiento de la disciplina, que se concretaban con un completo cuadro de acciones de carácter civil para la defensa de los intereses afectados por el acto de competencia desleal (arts. 18) y por aquel entonces, con un avanzado régimen de legitimación activa para entablar las acciones judiciales por competencia desleal (art. 19) que, junto a la tradicional legitimación individual, contemplaba la posible legitimación colectiva que se atribuía a las asociaciones de profesionales y de consumidores. ${ }^{7}$ Por último, la Ley también incluía algunas especificidades procesales para una mayor eficacia y celeridad en las causas por competencia desleal, entre las que cabe destacar, el régimen de medidas cautelares del art. 25 de la Ley. ${ }^{8}$

En España, la última gran reforma de la disciplina de la competencia desleal se produce en 2009 con la transposición al ordenamiento español de la Directiva 2005/29/CE del Parlamento Europeo y del

\footnotetext{
García Pérez (2007): En Derecho de los negocios, No 200, p.7, la finalidad por la que el legislador utiliza esta técnica legislativa es la de delimitar el ámbito de aplicación de la Ley frente a otras normas de nuestro ordenamiento, en particular, el art. 1902 del Código Civil, precepto dedicado a la responsabilidad civil extracontractual y en el que primariamente se había basado la disciplina de la competencia desleal.

Massaguer Fuentes (1999) p.57. En opinión del autor esta avanzada legislación se deja sentir especialmente en el régimen de la legitimación activa y pasiva, que se completa con ciertas previsiones procedimentales de extraordinaria importancia práctica, como son las relativas a las diligencias preliminares para la comprobación de hechos, las medidas cautelares o la atribución al juez de la potestad de exigir al demandado la prueba de ciertos extremos.

$8 \quad$ Ortells Ramos y Bellido Penadés (1999) pp.92-94.
} 
Consejo, de 11 de mayo de 2005, relativa a las prácticas comerciales desleales de las empresas en sus relaciones con los consumidores en el mercado interior, más conocida como Directiva de prácticas comerciales desleales. La citada Directiva fue transpuesta mediante la aprobación de la Ley 29/2009, de 30 de diciembre, por la que se modificó el régimen legal de la competencia desleal y de la publicidad para la mejora de la protección de los consumidores y usuarios (en adelante, Ley 29/2009), convirtiéndose esta reforma en la más importante que ha experimentado con carácter general la disciplina de la competencia desleal espańola en los últimos tiempos, si bien es cierto que, por el carácter limitado de la misma, en el que solo se atendía a la armonización plena de las prácticas comerciales desleales con los consumidores y usuario y en la que no se anunciaban mecanismos efectivos con los que hacer frente a estas prácticas comerciales desleales, no ha tenido tan buenos resultados como anunciaba. Por eso, próximamente, la actualidad comunitaria en materia de prácticas comerciales desleales se centra en la aprobación de un nuevo acuerdo para los consumidores que, entre otros aspectos, propone una modificación de la Directiva 2005/29/CE, en el que se velará por una mayor protección de los consumidores contra las prácticas comerciales desleales. ${ }^{9}$

La solución elegida por el legislador español para dar cumplimiento a los mandatos de la Directiva 2005/29/CE mediante la modificación de la LCD (1991) era la mejor opción posible, sin embargo, el legislador se equivoca en su ejecución, al distinguir en la LCD dos bloques en función del sujeto perjudicado por la práctica: ${ }^{10}$ Capítulo II dedicado a los actos de competencia desleal, que tendría un carácter general, y Capítulo III dedicado a los actos de competencia desleal con consumidores y usuarios. Centrándonos ahora en las razones que avalan la oportunidad de transponer el régimen de la Directiva de prácticas comerciales desleales en la LCD, podrían sintetizarse en tres argumentos.

En primer lugar, la LCD de 1991 ya disponía de un articulado que hacía referencia a su finalidad, disposiciones generales, cláusula general y tipificación de supuestos particularmente desleales, por lo que el régimen de la citada Directiva, centrado en una nueva cláusula general de deslealtad aunque circunscrita a las relaciones de consumo y el desarrollo de dos tipos de prácticas comerciales desleales como son las prácticas engañosas y agresivas, no resultaba extraño al hasta entonces seguido en la configuración de la Ley española contra la competencia desleal.

En segundo lugar, en España, las comunidades autónomas también tienen reconocidas competencias en materia de consumo. Por tanto, la transposición a través de la legislación de consumo, como hicieron Italia o Francia, presentaba como problema adicional, el posible cuestionamiento de la distribución de competencias entre el Estado y las comunidades autónomas, además de confundir el ya de por sí complejo marco normativo espańol en materia de consumo.

En tercer lugar, en el supuesto español, la opción de efectuar la transposición de la Directiva mediante la aprobación de una ley especial hubiese quebrantado la unidad legislativa para la represión de las prácticas comerciales desleales con el que se contaba en España. En efecto, esta opción implicaba dar un paso hacia atrás en la regulación de la disciplina de la competencia desleal que, como sabemos, había vencido su problema de dispersión normativa con la aprobación de la LCD (1991). ${ }^{11}$

\footnotetext{
comisión europea, Propuesta de Directiva del Parlamento Europeo y del Consejo por la que se modifican la Directiva 93/13/CEE del Consejo, de 5 de abril de 1993, la Directiva 98/6/CE del Parlamento Europeo y del Consejo, la Directiva 2005/29/CE del Parlamento Europeo y del Consejo y la Directiva 2011/83/UE del Parlamento Europeo y del Consejo, en lo que atañe a la mejora de la aplicación y la modernización de las normas de protección de los consumidores de la UE. [COM (2018) 185 final].

10 Tato Plaza, Fernández Carballo-Calero y Herrera Petrus (2010) p. 44.

11 Esta opción, lejos de simplificar el régimen de la competencia desleal, hubiese implicado, como señalaba la doctrina acreditada, una excesiva fragmentación del Derecho espańol de la competencia desleal, construyendo una legislación especial y artificiosa sobre prácticas engańosas
} 
No obstante, el objeto de protección de la Directiva de prácticas comerciales desleales, en el que solo se atiende a la protección de los consumidores frente a este tipo de prácticas, entendiéndose estos como "cualquier persona física que, en las prácticas comerciales contempladas por la presente Directiva, actúe con un propósito ajeno a su actividad económica, negocio, oficio o profesión» (art. 2, letra a) y los distintos tratamientos otorgados por el legislador espańol en la trasposición en función del sujeto destinatario de la práctica, han empañado, los buenos resultados que se esperaban con la aprobación de este nuevo régimen en España.

\section{La discriminación a los consumidores como práctica desleal}

\subsection{Cuestiones introductorias}

En el ordenamiento español, la discriminación a los consumidores como acto de competencia desleal, se regula en el art. 16 de la LCD bajo la rúbrica «Discriminación y dependencia económica», con la siguiente redacción:

«1. El tratamiento discriminatorio del consumidor en materia de precios y demás condiciones de venta se reputará desleal, a no ser que medie causa justificada. 2. Se reputa desleal la explotación por parte de una empresa de la situación de dependencia económica en que puedan encontrarse sus empresas clientes o proveedores que no dispongan de alternativa equivalente para el ejercicio de su actividad. Esta situación se presumirá cuando un proveedor, además de los descuentos o condiciones habituales, deba conceder a su cliente de forma regular otras ventajas adicionales que no se conceden a compradores similares. 3.Tendrá asimismo la consideración de desleal: a) La ruptura, aunque sea de forma parcial, de una relación comercial establecida sin que haya existido preaviso escrito y preciso con una antelación mínima de seis meses, salvo que se deba a incumplimientos graves de las condiciones pactadas o en caso de fuerza mayor. b) La obtención, bajo la amenaza de ruptura de las relaciones comerciales, de precios, condiciones de pago, modalidades de venta, pago de cargos adicionales y otras condiciones de cooperación comercial no recogidas en el contrato de suministro que se tenga pactado».

El lector habrá advertido que el precepto regula dos actos distintos de competencia desleal. El apartado primero, se dedica al tratamiento discriminatorio del consumidor y el apartado segundo y tercero a los supuestos de dependencia económica. La opción legislativa de ubicar en un mismo precepto la regulación de dos comportamientos desleales que no guardan relación entre sí es discutible porque carece de justificación, tanto desde una perspectiva sistemática como sustantiva. ${ }^{12}$ Como se estudiará en el siguiente epígrafe, el precepto, a lo largo de su vigencia ha sufrido modificaciones que han contribuido a mejorar su redacción, sin embargo, la opción de tratar en un mismo precepto la discriminación al consumidor y la dependencia económica, se ha conservado.

\subsection{Evolución legislativa del art. 16 de la LCD}

En el año 1991, cuando se promulgó la Ley española de competencia desleal, la redacción del art. 16 de la Ley, solamente constaba de dos párrafos y la rúbrica de este era simplemente: «Discriminación». Sin

y agresivas con consumidores, poniendo en último término en peligro la interpretación de la disciplina y contribuyendo aún más si cabe, a obscurecer el complicado panorama legislativo de la competencia desleal. Massaguer Fuentes, Marcos y Suńol (2006)N. 2013, pp. 19251963.

12 Massaguer Fuentes (1999), p.470. 
embargo, solo el primer párrafo estaba dedicado propiamente a la discriminación. El segundo, se dedicaba a los supuestos de dependencia económica, que no siempre se producirían a través de la discriminación. Por tanto, la Ley contemplaba dos supuestos de naturaleza diferente bajo una misma rúbrica que no se correspondía con el contenido del precepto. En consecuencia, el precepto era criticado por su deficiencia, especialmente por lo que respecta a la inadecuada rúbrica del artículo. ${ }^{13}$

La redacción actual que presenta el precepto y que hemos reproducido al inicio de este trabajo, se debe principalmente a la intervención legislativa introducida por la Disposición Adicional Tercera de la Ley 52/1999, de 28 de diciembre, de reforma de la, hoy derogada, Ley de Defensa de la Competencia de 17 de julio de 1989, que ańadió el actual tercer párrafo del art. 16 y reformó la criticada rúbrica del precepto, quedando de la siguiente manera: «Discriminación y dependencia económica».

Tras esta reforma, el actual precepto consta de tres párrafos, uno dedicado a la discriminación con consumidores y el segundo y tercero dedicado, como hemos expuesto, a los supuestos de explotación de una situación de dependencia económica como actos de competencia desleal. El art. 16 de la LCD, por tanto, recoge dos actos de competencia desleal diferentes, con criterios de deslealtad diferentes y con distintos ámbitos subjetivos, a saber, el apartado primero se refiere al consumidor y el apartado segundo a las empresas respecto a las que sus clientes o proveedores se hallan en una situación de dependencia económica.

\subsection{El tratamiento discriminatorio del consumidor}

El apartado primero del art. 16 de la LCD establece que: «El tratamiento discriminatorio del consumidor en materia de precios y demás condiciones de venta se reputará desleal, a no ser que medie causa justificada». De la redacción del primer apartado de la Ley, se pueden realizar las siguientes observaciones.

En primer lugar, el precepto contempla como desleal la discriminación a los consumidores. La determinación del concepto de discriminación se trata de una cuestión compleja, que se ha venido relacionando con connotaciones de derechos fundamentales que dificultan su interpretación. En este sentido, puede citarse la sentencia del Tribunal de Justicia de la Unión Europea, de 1 de marzo de 2011, Asunto C-236/09, que resuelve una cuestión prejudicial en un conflicto que enfrentaba a una Asociación belga de consumidores contra el Gobierno del mismo país por la transposición de la Directiva 2004/113, sobre igualdad de trato entre hombres y mujeres en el acceso a bienes y servicios y su suministro. En particular, en el citado supuesto se cuestionaba si la práctica de tomar en consideración el sexo del asegurado como elemento de discriminación en la determinación de la prima de los contratos de seguro, era incompatible con la citada Directiva. A este respecto, la sentencia declara incompatible con la igualdad, la normativa y práctica aseguradora centrada en la discriminación por razón del sexo en la determinación de la prima de los contratos de seguro. ${ }^{14}$

El análisis de la conducta que se reputa desleal en el art. 16.1 de la LCD, exige fijarse en el concepto constitucional de igualdad y no discriminación, para posteriormente plantearse su incidencia en el Derecho de la competencia desleal. El art. 14 de la Constitución espańola reconoce, como derecho fundamental, la igualdad de todos los españoles ante la ley sin que pueda prevalecer discriminación alguna por razón de nacimiento, raza, sexo, religión, opinión o cualquier otra condición o circunstancia personal o social. Se trata esta de una igualdad jurídica, es decir, legal, y no una igualdad real, es decir, que lo que viene

13 Alonso Soto (1992) en Bercovtiz p.90. Sobre este aspecto, también puede consultarse Bellido (2011) en Bercovtiz p.438.

14 Veiga Copo y Sánchez Graells (2011) Revista de Responsabilidad Civil, No 4, pp. 20 - 21. 
constitucionalmente exigido es que de supuestos de hecho iguales se deriven idénticas consecuencias jurídicas. ${ }^{15}$ Por ello, en la práctica, se distinguiría entre discriminación y diferenciación. Mientras que la primera se consideraría injustificada y no razonable, la segunda, se admitiría ante situaciones que tengan una base objetiva y razonable.

En coherencia con el anterior planteamiento, el art. 16 de la LCD se basa en la injusticia de la discriminación y a tal efecto considera desleal el tratamiento discriminatorio a los consumidores, en el sentido de que se trate de manera diferente a quienes se encuentran en igualdad de condiciones. ${ }^{16}$ De manera que, la discriminación, y, por tanto, la conducta típica, solo existirá cuando, en igualdad de situaciones, se adopten conductas empresariales desiguales que no encuentren una justificación objetiva.

El art. 16.1 de la LCD nombra expresamente a los consumidores por lo que cabe entender que estos serán los destinatarios naturales que el ilícito trata de tutelar. Sin embargo, este precepto no se integra en el Capítulo III de la LCD titulado «Prácticas comerciales con consumidores o usuarios», sino que lo hace en el Capítulo II «Actos de competencia desleal» con un alcance, como se ha señalado, general. El precepto tampoco se enumera entre las prácticas que se consideran desleales con los consumidores (art. 19 de la LCD): «1. Sin perjuicio de lo establecido en los artículos 19 y 20 del texto refundido de la Ley General para la Defensa de los Consumidores y Usuarios y otras leyes complementarias, únicamente tendrán la consideración de prácticas comerciales desleales con los consumidores y usuarios, las previstas en este capítulo y en los artículos 4, 5, 7 y 8 de esta ley. 2. Las prácticas comerciales reguladas en los artículos 21 a 31 , ambos inclusive, son en todo caso y en cualquier circunstancia, prácticas comerciales desleales con los consumidores».

Los posibles argumentos que justificarían la opción legislativa, es que la redacción del ilícito es anterior a la aprobación de la Directiva 2005/29/CE sobre prácticas comerciales desleales. Además, en esta Directiva, no se contempla expresamente como práctica comercial con consumidores y usuarios, las prácticas de discriminación, sino que solamente reciben la consideración de prácticas desleales con consumidores y usuarios, las prácticas engañosas y las prácticas agresivas. ${ }^{17}$

Por ello, en la reforma producida en la LCD por la Ley 29/2009 con ocasión de la transposición de la Directiva de prácticas comerciales desleales al ordenamiento espańol, el precepto quedó sin modificar. No obstante, se apreciaría una incongruencia en la estructura de la actual LCD, puesto que el art. 19 no menciona al art. 16.1 entre aquellas prácticas comerciales desleales con consumidores o usuarios, siendo los consumidores los sujetos pasivos del ilícito. Ello se debe a que el legislador en la transposición de la citada Directiva al ordenamiento espańol adopta una fórmula deficiente, decidiendo reproducir literalmente la estructura de la Directiva de prácticas comerciales desleales en la LCD. Esta estructura de la Directiva, no se ajustaba a la seguida en la LCD hasta la fecha, en la que, como se ha señalado, no se distinguía en función del sujeto perjudicado por la práctica. El resultado es que actualmente la LCD distingue en dos bloques, entre actos de competencia desleal en general y con consumidores o usuarios, en función del sujeto perjudicado. La distinción efectuada es artificial y dificulta la interpretación de la Ley, por lo que ha recibido duras críticas por la doctrina. ${ }^{18}$

\footnotetext{
Porfirio Carpio (2002) pp.79 y 86.

Alonso Soto (1992) p.89.

Howells (2007) pp.108 y 109.

8 Tato Plaza, Fernández Carballo-Calero y Herrera Petrus (2010) pp.51-57.
} 
Aunque se han ofrecido algunas razones que justificarían la opción legislativa elegida, por ejemplo, que el art. 16.1 de la LCD dedicado al tratamiento discriminatorio del consumidor quedaría al margen de las previsiones de la Directiva de prácticas comerciales desleales, que solo armoniza la regulación de las prácticas engańosas y agresivas, se advierte una deficiente formulación en la LCD en el tratamiento discriminatorio al consumidor, pues esta práctica, aunque tenga como objeto la protección de los consumidores, no formaría parte de las prácticas integradas en el Capítulo de "prácticas comerciales con consumidores o usuarios».

Además, en relación con este último aspecto, téngase en cuenta que la Directiva de prácticas comerciales desleales es de armonización plena y de máximos. De manera que, la cuestión a dilucidar para determinar si el art. 16.1 de la LCD sería compatible con la Directiva de prácticas comerciales desleales, es si el precepto forma parte del ámbito no armonizado de la Directiva, y, en consecuencia, el legislador espańol puede mantener el precepto o si, por el contrario, no sería compatible con la citada Directiva. La cuestión es compleja, pues si se llegase a la conclusión de que el precepto integra la noción de "práctica comercial con consumidores» en el sentido del texto comunitario, cualquier desviación con dicho texto no sería compatible con la armonización plena perseguida por la Directiva. Esta última conclusión, no parece que sea la que se alcanzaría después de analizar conjuntamente el controvertido ámbito de aplicación del art. 16.1 de la LCD y la Directiva de prácticas comerciales desleales. ${ }^{19}$

Otra cuestión problemática en relación con el precepto que estamos comentando, es la noción de consumidor que se tomaría en consideración para determinar el ámbito subjetivo del precepto. La LCD no se ha pronunciado sobre el concepto consumidor. Por su parte, la Directiva de prácticas comerciales desleales sí que ha definido qué se entiende por consumidor a los efectos de la Directiva (art. 2 letra a) y que ya hemos reproducido en este trabajo. Sobre este aspecto, téngase en cuenta que la citada Directiva no contempla la posibilidad de que las personas jurídicas puedan ser consideradas consumidoras o usuarias. Sin embargo, en el ordenamiento espańol, ${ }^{20}$ el Real Decreto Legislativo 1/2007, de 16 de noviembre, por el que se aprueba el texto refundido de la Ley General para la Defensa de los Consumidores y Usuarios y otras leyes complementarias (en adelante, TRLGDCU), norma que es de aplicación a las relaciones entre consumidores o usuarios y empresarios (art. 2), considera consumidores o usuarios a los efectos de esa Ley a «las personas físicas que actúen con un propósito ajeno a su actividad comercial, empresarial, oficio o profesión» (art. 3, párrafo primero) y también a «las personas jurídicas y las entidades sin personalidad jurídica que actúen sin ánimo de lucro en un ámbito ajeno a una actividad comercial o empresarial» (art. 3, párrafo segundo). De la lectura conjunta del párrafo primero y segundo del art. 3, se desprende que se establecen diferentes criterios para la consideración de consumidor a las personas físicas que, a las jurídicas, pero ambas pueden ser consideradas consumidoras. En consecuencia, a diferencia de la noción de consumidor que baraja el texto comunitario, el ordenamiento español mantiene la posibilidad de que también las personas jurídicas puedan ser consumidoras. La nota que caracterizaría el concepto de consumidor en la persona jurídica es, como hemos señalado, la falta de ánimo de lucro y además que el bien o servicio adquirido no sea incorporado en procesos de producción, transformación, comercialización o prestación a terceros, presupuestos que no se cumplirían, por ejemplo, en el ejercicio de las relaciones

\footnotetext{
19 Algunos autores apuntan que el mantenimiento del art. 16 de la LCD tal y como está planteado es discutible, pudiendo dar lugar al planteamiento de una cuestión prejudicial en el futuro. En este sentido, Arroyo Aparicio, Alicia (2014) en García-Cruces pp.1483-1487; Tato Plaza, Fernández Carballo-Calero y Herrera Petrus (2010) p.57.

20 Reyes López (2020) en Pajín Echevarría, p. 70, existen criterios dispares en la noción de consumidor en función de la normativa consultada. En ocasiones el legislador utiliza la noción amplia, en otras, lo restringe o, por el contrario, ofrece una visión más amplia, permitiendo incluso que los empresarios puedan ser asemejados en el tratamiento al que reciben los particulares. Esta diversidad es debida a que cada norma concreta su ámbito de aplicación subjetivo, delimitando su operatividad con el término «a los efectos de esta ley», que al mismo tiempo que reitera su carácter sectorial, es un rasgo común a todas las disposiciones de consumo.
} 
comerciales con una pequeña y mediana empresa, aunque tenga menor capacidad de negociación que una empresa de mayor tamańo o más asentada en el mercado. De manera que, al tiempo de otorgar el grado de protección especial que la Ley dispensa, es necesario que se enfrenten, de una parte, los derechos de una persona que actúa en un ámbito ajeno a la actividad profesional o empresarial y de otra, los derechos de aquel que se desenvuelve dentro de su actividad profesional o empresarial.

Si se sostiene que el art. 16.1 de la LCD, no integra la noción de "práctica comercial con consumidores» que armoniza la Directiva de prácticas comerciales desleales, el concepto de consumidor que maneja el texto comunitario y que solo atiende, como hemos visto, a las personas físicas que cumplan con los presupuestos señalados por la Directiva, podrían no tenerse en cuenta para interpretar el término consumidor al que se refiere el art. 16.1 de la LCD. De manera que el citado precepto perseguiría el tratamiento arbitrario de un profesional que sea discriminatorio para un consumidor, tomándose en cuenta para la determinación del sujeto pasivo del ilícito, un concepto amplio de consumidor.

La escasa jurisprudencia española que existe sobre los supuestos de discriminación desleal del art. 16.1 de la LCD, en coherencia con la noción de consumidor que se defendía con la promulgación de la LCD en el año 1991 y que no se corresponde con la incorporada por la Directiva de prácticas comerciales desleales, ha tomado en cuenta una noción amplia de consumidor, extendiendo este concepto a la clientela en general. ${ }^{21}$ Si bien, hay que matizar que las resoluciones a las que nos referiremos a continuación son anteriores a la transposición de la Directiva 2005/29/CE de prácticas comerciales desleales al ordenamiento español y, por tanto, no se cuestionaba el concepto de consumidor al que se refería el precepto, puede apreciarse en la interpretación jurisprudencial del art. 16.1 de la LCD, que la norma es observada como un acto de competencia desleal que incide en las posibilidades de actuación de los participantes en el mercado en el que no se atiende, por tanto, a un concepto estricto de consumidor como el que defiende la Directiva de prácticas comerciales desleales.

Un ejemplo de la noción amplia de consumidor que se ha venido defendiendo por la jurisprudencia española en la aplicación del art. 16.1 de la LCD, es la Sentencia del Tribunal Supremo (Sala Civil), de 14 de marzo de 2007, en la que se plantea aplicar este precepto a un supuesto en el que es un distribuidor no exclusivo. El motivo se desestima porque no se consideró desleal la discriminación que aducía la entidad demandante por mediar causa justificada. El Tribunal entendió que no se acreditó en el presente supuesto una política discriminatoria de precios, o de condiciones de financiación más «duras» respecto a otros distribuidores o compradores de productos, así como apreció normalidad en el trato comercial. En el citado supuesto, como decimos, no se aprecia deslealtad por esta causa, sin embargo, lo relevante es que se cuestiona la posible aplicación del art. 16.1 de la LCD en un supuesto en el que las dos partes son empresarios.

También la Sentencia de la Audiencia Provincial de Girona, de 10 de febrero de 2005, en un caso en el que se plantea la posible aplicación del art. 16.1 de la LCD a un supuesto entre empresarios, hace referencia al concepto extensivo de consumidor y a este respecto establece que:

«La negativa repentina a que la aseguradora demandante siga manteniendo con ella los tratos y relaciones que tenía hasta ese momento, situación que no se impone a las demás aseguradoras de decesos, constituye una evidente discriminación en contra de aquélla. El art.16.1 de la indicada Ley exige que dicha discriminación se produzca respecto del consumidor. Teniendo en cuenta el ámbito de actuación de las empresas aseguradoras de decesos, no existiría inconveniente en considerarlas consumidoras de

${ }_{21}$ Arroyo Aparicio (2014), p. 1492 y Álvarez Rubio (2016) en De León Arce y García García, p. 2465. 
los servicios que prestan las funerarias, sin que este concepto jurídico pudiera predicarse tan solo de las personas físicas o jurídicas que, por razones de amistad, de parentesco o de cualquiera otra índole con el difunto, encargan la prestación de tales servicios.

Pero aún si se mantuviese este concepto restrictivo de consumidor, lo cierto es que la actuación de la demandada sería igualmente discriminatoria para los asegurados de la demandante. Ello es así porque si hasta ese momento la empresa de servicios funerarios permitía que fuesen los agentes de la aseguradora los que se ocupasen de todos los trámites inherentes a la contratación de servicios de la primera por cuenta de los asegurados, girando las facturas derivadas de los mismos no a tales asegurados en tanto que consumidores del producto sino a la propia aseguradora, práctica que sigue manteniendo con los asegurados de otras empresas, cesar en dicho modo de operar tan solo respecto de los asegurados de la demandante, implica una evidente discriminación y un trato desleal hacia estos últimos, que se ven impedidos de actuar ante la funeraria de una forma más cómoda y ágil que les permite, entre otras cosas, no tener que efectuar desembolso previo alguno para después resarcirse del mismo ante la aseguradora».

En este supuesto, la Audiencia Provincial de Girona, concluye que el comportamiento descrito entra de lleno en la previsión del art. 16.1 de la LCD, por entender que la actuación de la empresa había sido discriminatoria tanto si se entendía que las aseguradoras de decesos se incluían en el concepto de consumidores de servicios funerarios, como si se restringía esta consideración a sus asegurados.

Desde la otra perspectiva, es decir, desde la óptica del sujeto que realiza el tratamiento discriminatorio, aunque no está delimitado expresamente por el legislador en el art. 16.1 de la LCD, a diferencia de lo que ocurre en el apartado segundo del precepto, parece claro que se corresponde con aquellos empresarios, profesionales y cualesquiera otras personas físicas o jurídicas que participen en el mercado, a los que se refiere en sentido amplio el art. $3 \mathrm{LCD}^{22}$ : «Ámbito subjetivo. 1. La ley será de aplicación a los empresarios, profesionales y a cualesquiera otras personas físicas o jurídicas que participen en el mercado. 2. La aplicación de la Ley no podrá supeditarse a la existencia de una relación de competencia entre el sujeto activo y el sujeto pasivo del acto de competencia desleal». Por tanto, cualquier persona, aunque no se trate de un operador económico de carácter profesional, queda sujeta a la LCD, si realiza actos en el mercado que puedan calificarse de competencia desleal, en el supuesto ahora analizado, si realiza actos de discriminación desleales en el sentido del art. 16.1 de la LCD. ${ }^{23}$

Siguiendo con la exégesis del precepto, el primer apartado del art. 16 de la LCD, concreta la deslealtad en el tratamiento discriminatorio del consumidor en los precios y demás condiciones de venta.

Podría entenderse la discriminación en materia de precios, de manera general, como una variación en la relación precio-coste entre unidades o entre grupos de compradores. Esta noción amplia de la referencia de la discriminación al consumidor en materia de precios permitiría incluir ejemplos de precios múltiples cuando los costes no difieren, como vender un vehículo idéntico a dos compradores diferentes a dos precios

Arroyo Aparicio (2014) p.1495.

23 En la primera versión de la norma, no se apuntaba la posibilidad de que también se pudiese aplicar a los profesionales, solo se hacía referencia expresa a los empresarios. En la práctica, este descuido del legislador no supuso que la Ley no se aplicase a los profesionales. Así lo entendió la doctrina Otamendi Rodríguez Bethencourt (1994) p. 128 y los tribunales, por ejemplo, la Sentencia del Tribunal Supremo (Sala Civil), de 18 de octubre de 2000. Posteriormente con ocasión de la transposición de la Directiva 2005/29/CE al ordenamiento español, la LCD se reforma en este aspecto, y se zanja la discusión, reconociéndose expresamente a los profesionales en el ámbito subjetivo de la norma. Sin embargo, la innovación introducida después de la reforma con la referencia a profesionales tiene escasa importancia práctica, porque el propio art. 3 de la LCD añade que la ley es de aplicación «a cualesquiera otras personas fisicas o jurídicas que participen en el mercado». Bercovtiz, Alberto (2011): en Bercovtiz, p.87. 
diferentes, y precios únicos cuando los costes difieren, como enviar el mismo bien a dos compradores diferentes en diferentes ubicaciones y costes, pero al mismo precio entregado. ${ }^{24}$

Como es sabido, en materia de fijación de precios, el empresario o profesional es, en principio, libre. Esta libertad del profesional para fijar los precios a los que desea ofertar sus productos o servicios forma parte del contenido esencial del principio constitucional de la libertad de empresa. Si bien el empresario o profesional no es totalmente libre para determinar los precios de venta de sus productos o servicios si implica un trato diferenciador no justificado entre consumidores, es decir, un supuesto de discriminación desleal. El trato desigual en materia de precios no se refiere única y exclusivamente a la fijación del precio, sino que, como ha señalado la doctrina, ${ }^{25}$ también se refiere a la transmisión de información de precios y a la incidencia de las formas de pago en el precio final del producto o servicios. En este sentido, la obligación informativa en cuanto al precio que tiene el empresario con el consumidor cumple con dos objetivos fundamentales: por un lado, se protege la libertad de elección del consumidor, y por otro, se impide discriminar entre consumidores, aplicando los precios de manera individualizada. Por tanto, este deber del empresario dificulta la aparición del supuesto de hecho que ahora analizamos.

En cuanto a la referencia a las «demás condiciones de venta» de la que habla el precepto, se trata de una casuística muy variada que escapa de cualquier tipo de sistematización, puesto que no sería factible establecer un elenco de todas las posibles condiciones de venta, además del precio, que pueden resultar discriminatorias. ${ }^{26}$ Algunos ejemplos serían, la negativa de venta o en condiciones más favorables de pago. También aquellos supuestos de fidelización a los consumidores en los que la aplicación de distintas condiciones a unos u otros clientes fuera discriminatoria de manera injustificada. ${ }^{27}$ Esta última matización, nos lleva a recordar que para considerar desleal la discriminación al consumidor en materia de precios y demás condiciones de venta, esta ha de hacerse sin causa justificada.

\subsection{Justificación de la discriminación}

Tal y como se desprende del art. 16.1 de la LCD, solamente la discriminación a los consumidores se reputa desleal si no media causa justificada, entendiéndose como motivo de justificación, una causa objetiva. Como ha seńalado la doctrina, ${ }^{28}$ con ello, no debe entenderse que la injusticia generada por el trato discriminatorio a los consumidores puede ser tolerada en algunos supuestos y en otros no, sino que esta referencia debe ser entendida como una forma de disipar la confusión entre discriminación y diferenciación que, como hemos expuesto, se trata de dos supuestos bien distintos. En definitiva, con esta previsión, se prohíbe el trato discriminatorio de los consumidores realizado de manera arbitraria.

Las causas de justificación para considerar que la discriminación no es desleal pueden ser diversas. Se ha señalado ${ }^{29}$ por ejemplo, que no se consideraría discriminatorio el hecho de que a un consumidor se le cobre un precio más barato si paga al contado que aquel que lo hace fraccionando el pago. Tampoco si se aplican precios de venta distintos en función del volumen de compra o si se contrata servicios conexos de mantenimiento. Del mismo modo no se puede considerar que la discriminación entre consumidores carezca de una justificación razonable cuando el fabricante del producto adquirido rechaza la garantía

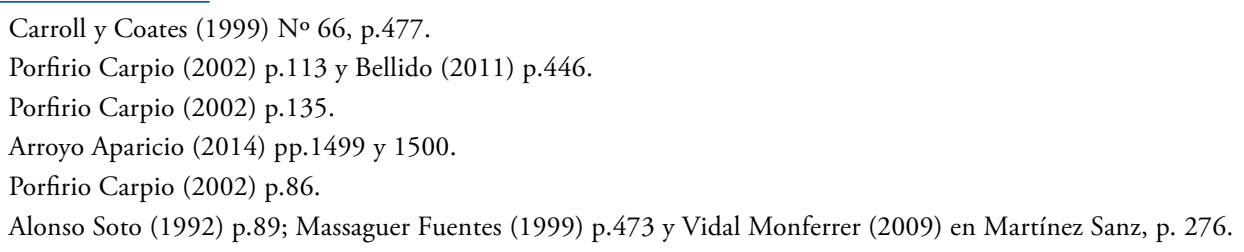


por haber sido adquirido fuera del canal de distribución autorizado, siendo este un hecho notorio que se acostumbra a reflejar en muchas condiciones generales, por ejemplo, en el ámbito de la electrónica de consumo. Tampoco se considera discriminación que una compañía aérea se reserve el derecho a embarcar a los pasajeros que hayan adquirido sus billetes eludiendo el único sistema de distribución autorizado. ${ }^{30}$ Todos estos supuestos se encontrarían amparados por la justificación objetiva que contempla el precepto. En todos resulta claro que el empresario no estaría obligado a contratar en iguales términos con todos los clientes, siendo el límite la discriminación injustificada objetivamente.

No obstante, existen otros supuestos de discriminación, en los que no está tan claro que no puedan reputarse desleales. Por ejemplo, se cuestiona si son desleales por esta causa, las prácticas realizadas a través de Internet en las que se discrimina a los consumidores con base en su lugar de residencia o de nacionalidad a través de técnicas de geobloqueo. ${ }^{31}$ La discriminación, puede consistir en el rechazo a vender a consumidores localizados en Estados distintos a aquel del vendedor, o la imposición de precios más altos o en condiciones distintas. ${ }^{32}$ Por ejemplo, los consumidores han acusado de prácticas discriminatorias basadas en geobloqueo, a un conocido parque de atracciones ubicado en Paris, por bloquear el acceso a las ofertas más baratas, disponibles solo para los consumidores franceses o belgas, incumpliendo la Directiva de servicios. ${ }^{33}$ También, recientemente la Comisión Europea ha multado a un grupo hotelero por haber discriminado a los clientes al suscribir contratos con operadores turísticos que limitaban las ventas activas y pasivas de alojamientos hoteleros en función del lugar de residencia del consumidor. ${ }^{34}$ Las técnicas de localización geográfica para diferenciar o discriminar entre los clientes, se basan en datos como la dirección IP del cliente, su lugar de residencia o de establecimiento, el idioma que elige para manejarse en Internet, o el país de expedición de su tarjeta de pago. ${ }^{35}$

En el supuesto de prácticas de geobloqueo, al igual que los otros supuestos de discriminación, también se debe distinguir entre prácticas de geobloqueo justificadas y no justificadas. Según un estudio del Parlamento europeo ${ }^{36}$ para prevenir el geobloqueo y otras formas de discriminación de los consumidores, encargado por la Comisión de Mercado Interior y Protección del Consumidor del Parlamento Europeo, las prácticas de bloqueo geográfico injustificadas se basaban en razones puramente comerciales y tendrían como objetivo principal participar en estrategias de discriminación de precios o influir en la competencia. Dichas prácticas podrían resultar de decisiones unilaterales de los comerciantes en línea u obligaciones contractuales (por ejemplo, de acuerdos verticales entre proveedores y distribuidores) que prohibirían a los comerciantes vender productos transfronterizos. En cambio, las prácticas de geobloqueo justificadas serían los casos en que los comerciantes no venden en el comercio transfronterizo: i) como resultado de obligaciones legales que provienen de la UE y de las normas nacionales (por ejemplo, leyes de derechos de autor, normas sobre publicidad, normas sobre ciertos productos o servicios prohibidos tales como tabaco, alcohol y juegos de azar, protección de menores); o ii) cuando de hacerlo, incurrirían en costes de

30 Las consideraciones de la Sentencia del Juzgado de lo Mercantil no 1 de Madrid de 13 de septiembre de 2010.

31 Martí Moya (2020) p. 20, el Geobloqueo de compras transfronterizas en línea significa discriminar a los consumidores por motivos de residencia o nacionalidad. Es un problema poliédrico que puede ser estudiado desde varios ámbitos del ordenamiento jurídico, entre los que se encuentra el Derecho de defensa de la competencia y también el Derecho de la competencia desleal.

32 Martí Moya (2016/2017) ADI, No 37, p. 74.

33 Martí Moya (2020) p.67, que se hace eco de la mayor preocupación de la Comisión por la lucha contra las prácticas discriminatorias, como demuestra la investigación abierta contra un gran parque de atracciones europeo por aplicar precios diferentes a los clientes por razón de su nacionalidad. En este caso, la mera apertura de la investigación, así como la fuerte presión recibida implicó un cambio en la política de precios del parque.

34 Comisión Europea "Comunicado de prensa» de 21 de febrero de 2020.

35 Arpio Santacruz (2018) RCD, № 22.

36 European Parliament (2016) Disponible en https://www.ceps.eu/ceps-publications/combating-consumer-discrimination-digital-single-market-preventing-geo-blocking-and/ [Fecha de consulta: 04.03.2020] 
adaptación desproporcionados debido a restricciones regulatorias (por ejemplo, normas de iva, sistemas fiscales, derecho del consumidor, derecho contractual, requisitos de etiquetado) y otros obstáculos a las ventas transfronterizas (por ejemplo, calidad y costes de los servicios de entrega). Sin embargo, el citado estudio apuntaba que aceptar la legalidad de la discriminación entre consumidores de la ue por su nacionalidad o lugar de residencia sobre la base de justificaciones objetivas, podría resultar un obstáculo que reduciría el alcance de cualquier iniciativa en el campo del Mercado Único Digital, además de preservar la fragmentación del mercado.

Para paliar los efectos negativos que pueden generar las prácticas de geobloqueo, la Comisión dio un paso más, y aprobó el Reglamento 2018/302, de 28 de febrero de 2018, sobre medidas destinadas a impedir el bloqueo geográfico injustificado y otras formas de discriminación por razón de la nacionalidad, del lugar de residencia o del lugar de establecimiento de los clientes en el mercado interior y por el que se modifican los Reglamentos (CE) núm. 2006/2004 y (UE) 2017/2394 y la Directiva 2009/22/CE, que aborda aquellos casos en que las empresas, de forma unilateral y sin que la transnacionalidad de la operación suponga dificultades ańadidas o costes adicionales considerables, deciden rechazar el acceso de los consumidores a su oferta comercial por razón de su residencia, establecimiento o nacionalidad. Sin embargo, como ha señalado la doctrina, ${ }^{37}$ la norma tiene un alcance muy limitado, resultando solamente aplicable a situaciones concretas, considerablemente puntuales.

Además de las prácticas comerciales que hemos visto que pueden constituir una forma de discriminación a los consumidores, recientemente se ha cuestionado si la creación de espacios solo para adultos puede suponer una práctica de discriminación al consumidor encubierta. Esta cuestión no nos resulta baladí. Existe actualmente una tendencia a crear locales comerciales en los que no se admiten niños, que se ha extendido a hoteles, restaurantes, vagones de trenes, líneas aéreas o cines. Sobre la posible ilicitud de esta práctica, existen posiciones contrapuestas. Mientras que algunos defienden que prohibir la entrada de un niño en local abierto al público es un acto discriminatorio y, por lo tanto, ilegal, que no encontraría ninguna justificación objetiva, otros, amparándose en la libertad de empresa reconocida en el art. 38 de la Constitución española, afirman que los empresarios tienen derecho a elegir a sus clientes o la forma en la que quieren relacionarse con ellos. ${ }^{38}$ Pensamos que la práctica descrita no se trata de un supuesto de discriminación, pues el profesional amparándose en la libertad de empresa, podría dirigir su publicidad y sus servicios a un público solo adulto y no incurriría en deslealtad alguna. Con todo, el debate en relación con esta posible nueva forma de discriminación está abierto.

\section{Conclusiones}

El tratamiento que recibe la discriminación de los consumidores en la Ley de Competencia Desleal española adolece, como se ha apuntado en este trabajo, de algunas deficiencias.

En primer lugar, no se explica por qué los supuestos de discriminación a los consumidores están regulados en el mismo precepto que los de dependencia económica. Como hemos analizado en este trabajo, art. 16 de la LCD aglutina dos supuestos heterogéneos de actos de competencia desleal que no guardan relación entre sí. Aunque se aplauden los esfuerzos del legislador por mejorar la redacción del precepto, por ejemplo,

Martí Moya (2020) p.32.

38 En prensa, «Restaurante con o sin niños», en https://www.lavanguardia.com/vida/20190102/453884149071/presencia-ninos-restaurantes-debate.html o «Hoteles solo para adultos, un servicio en auge que bordea los límites de la discriminación por edad», en https://www. eldiario.es/nidos Hoteles-adultos-servicio-limites-discriminacion_0_796521116.html. 
la actual rúbrica del precepto «Discriminación y dependencia económica», en la que se contemplan los dos actos de competencia desleal que trata el precepto, no se justifica, ni desde una perspectiva sistemática ni sustantiva, el tratamiento de estos dos comportamientos desleales en un mismo precepto.

En segundo lugar, el art. 16 de la LCD aunque no se incluye entre los actos de competencia desleal con consumidores que menciona el art. 19 de la LCD ni tampoco en el Capítulo III de la LCD dedicado a los actos de competencia desleal con consumidores y usuarios, sus destinatarios naturales, al menos en los supuestos de discriminación, son los consumidores. Esta discrepancia, como hemos analizado en este trabajo, se debe a que en la transposición de la Directiva de prácticas comerciales desleales al ordenamiento español se dividió artificialmente la LCD en dos bloques: actos de competencia desleal, en general (Capítulo II) y actos de competencia desleal con consumidores y usuarios (Capítulo III). Sin embargo, no todos los supuestos de competencia desleal con consumidores y usuarios integran el Capítulo III de la Ley. Este es el caso del art. 16.1 de la LCD que se enmarca en el capítulo dedicado a los actos de competencia desleal, con carácter general. La explicación se debe a que la Directiva de prácticas comerciales desleales solamente contempló la armonización de las prácticas engañosas y agresivas con consumidores y usuarios. Este régimen es el que integra el Capítulo III de la Ley española de competencia desleal. Sin embargo, los supuestos del art. 16.1 de la LCD que también tienen como destinatarios naturales a los consumidores quedan desubicados de esta estructura artificiosa seguida por el legislador español.

El art. 16.1 de la LCD ha tenido escaso protagonismo en la práctica de los tribunales españoles, pese a que podría cuestionarse su utilidad para reprimir determinados actos de discriminación habituales en el mercado digital, como las técnicas de geobloqueo. Las pocas resoluciones que existen en este ámbito atienden a un concepto de consumidor que no es el estrictamente seguido por la Directiva de prácticas comerciales con consumidores y usuarios. El concepto de consumidor al que responden las resoluciones del art. 16.1 de la LCD no atiende únicamente a las personas físicas que actúan en un ámbito ajeno a su actividad profesional o empresarial, sino que también parece atender a las personas jurídicas, especialmente, pequeñas y medianas empresas, que han recibido un tratamiento discriminatorio por parte de otras empresas de mayor tamaño a más capacidad de negociación.

\section{Bibliografía citada}

Alonso Soto, Ricardo (1992): «Supuestos de competencia desleal por venta a pérdida y discriminación», en Bercovtiz, Alberto (coordinador), La regulación contra la Competencia desleal en la Ley de 10 de enero de 1991, (Madrid, Boletín Oficial del Estado. Cámara de Comercio e Industria de Madrid).

Álvarez Rubio, Julio (2016) «Protección del consumidor a través del Derecho de la Competencia» en De León Arce, Alicia (directora) y García García, Luz María (coordinadora), Derecho de los consumidores y usuarios (Valencia, Tirant lo Blanch, 3a edición, Tomo II) p. 2465.

Arpio Santacruz, Juan (2018): «Fundamento y alcance de la regulación europea sobre el bloqueo geográfico injustificado y otras formas de discriminación», $R C D$, № 22.

Arroyo Aparicio, Alicia (2014): «Discriminación y dependencia económica», en García-Cruces, José Antonio (coordinador), Tratado de Derecho de la competencia y de la publicidad (Valencia, Tirant lo Blanch) pp. 1483-1500.

Bellido, José (2011): «Artículo 16. Discriminación y Dependencia Económica» en Bercovtiz, Alberto, Comentarios a la Ley de Competencia Desleal, (Navarra, Thomsom Aranzadi) p. 438. 
Bercovtiz, Alberto (2011): «Artículo 3. Ámbito subjetivo» en Bercovtiz, Alberto, Comentarios a la Ley de Competencia Desleal, (Navarra, Thomsom Aranzadi) p. 87.

Carroll y Coates (1999): «Teaching Price discrimination: some clarification», Southern Economic Journal, No 66, p. 477.

Fernández-Nóvoa, Carlos (1978): «La interpretación jurídica de las expresiones publicitarias», $R D M$, No 107.

García Pérez, Rafael (2007): «El ámbito objetivo de aplicación de la Ley de Competencia Desleal», Derecho de los negocios, No 200, p. 7.

Gómez Segade, José Antonio (1974): El secreto industrial (Know-how). Concepto y protección (Madrid, Tecnos) pp. 389 y ss.

Howells (2007) «Unfair Commercial Practices Directive-A Missed Opportunity?» en Weatherill y Bernitz The Regulation of Unfair Commercial Practices under EC Directive 2005/29. New Rules and New Techniques (Portland, Hart Publishing) pp. 108 y 109.

Martí Moya, Vanessa (2016/2017): «El Mercado único digital y las restricciones a la competencia en el comercio online de bienes», $A D I$, No 37, p. 74.

Martí Moya, Vanessa (2020): Geobloqueo y comercio electrónico entre la libre circulación y el derecho de la competencia (Madrid, Agencia Estatal Boletín Oficial del Estado) p. 20.

Massaguer Fuentes, José (1999): Comentario a la Ley de Competencia Desleal (Madrid, Civitas).

Massaguer Fuentes, José; Marcos, Francisco y Suñol, Aurea (2006): «The Implementation into Spanish Law of EU Directive 2005/29/EC on Commercial Unfair Practices (in Spanish)», Boletín de información del Ministerio de Justicia, N. 2013, pp. 1925-1963.

Ménendez Menéndez, Aurelio (1988): La competencia desleal (Madrid, Civitas).

Ortells Ramos, Manuel y Bellido Penadés, Rafael (1999): Las medidas cautelares en el Derecho de la competencia: la práctica del Tribunal de defensa de la competencia y de los tribunales civiles, (Valencia, Tirant lo Blanch, Valencia) pp. 92-94.

Otamendi Rodríguezbethencourt, Juan José (1994): Comentarios a la Ley de competencia desleal (Pamplona, Aranzadi) p. 128.

Otero Lastres, José Manuel (1991-1992) «La nueva ley sobre competencia desleal», $A D I$, No 14, p. 30.

Porfirio Carpio, Leopoldo José (2002): La discriminación de consumidores como acto de competencia desleal (Madrid, Marcial Pons).

Reyes López, María José (2020), «Noción de consumidor y usuario» en Pajín Echevarría, Pablo (coordinador), GPS consumo, (Valencia Tirant lo Blanch) p. 70.

Tato Plaza, Anxo, Fernández Carballo-Calero, Pablo y Herrera Petrus, Christian (2010): La reforma de la Ley de Competencia Desleal (Madrid, La Ley).

Veiga Copo, Abel y Sánchez Graells, Albert (2011): «Discriminación por razón de sexo y prima del contrato de seguro. Apuntes críticos a la Sentencia del Tribunal de Justicia de la Unión Europea (Gran Sala), de 1 de marzo de 2011, en el asunto C-236/09 (Association belge des Consommateurs Test-Achats ASBL y otros contra Conseil des ministres)», Revista de Responsabilidad Civil, No 4, pp. 20 y 21.

Vidal Monferrer, Rosa María (2009): "Artículo 16. Discriminación y dependencia económica», en Martínez Sanz, Fernando (director), Comentario práctico a la Ley de Competencia Desleal (Madrid, Tecnos) p. 276. 


\section{Normas citadas}

Ley No 3 (10/1/1991) de Competencia Desleal.

Ley No29 (30/12/2009) por la que se modifica el régimen de la competencia desleal y de la publicidad para la mejora de la protección de los consumidores y usuarios.

Directiva No 29 (11/5/2005) relativa a las prácticas comerciales desleales de las empresas en sus relaciones con los consumidores en el mercado interior, que modifica la Directiva 84/450/CEE del Consejo, las Directivas 97/7/CE, 98/27/CE y 2002/65/CE del Parlamento Europeo y del Consejo y el Reglamento (CE) no 2006/2004 del Parlamento Europeo y del Consejo.

\section{Jurisprudencia citada}

Sentencia del Tribunal de Justicia de la Unión Europea, de 1 de marzo de 2011, Asunto C-236/09

Sentencia del Tribunal Supremo (Sala Civil), de 18 de octubre de 2000.

Sentencia del Tribunal Supremo (Sala Civil), de 14 de marzo de 2007.

Sentencia de la Audiencia Provincial de Girona, de 10 de febrero de 2005.

Sentencia del Juzgado de lo Mercantil no 1 de Madrid, de 13 de septiembre de 2010. 